\title{
Palmoplantar pustulosis
}

\section{David A. Wetter MD}

See also practice article by Lee and Ladizinski at www.cmaj.ca/lookup/doi/10.1503/cmaj.121036

Competing interests: None declared.

This article has been peer reviewed.

Affiliation: Department of Dermatology, Mayo Clinic, Rochester, Minn.

\section{Correspondence to:} David A. Wetter, wetter.david@mayo.edu

CMAJ 2013. DOI:10.1503 /cmaj.121143
$\mathrm{A}$ 46-year-old woman presented with a 5year history of recurrent and painful eruptions of pustules on her palms and the soles of her feet that resolved with redbrown discolouration. She did not have psoriatic skin lesions or nail findings. She had inflammatory arthritis (hands, wrists, feet, ankles, knees and sternoclavicular joint) with negative radiography of the hands for psoriatic arthritis. She had a history of smoking. Prior treatment with prednisone, methotrexate and infliximab had not improved her skin lesions or arthritis. Examination of her soles (Figure 1) and palms showed thin erythematous plaques

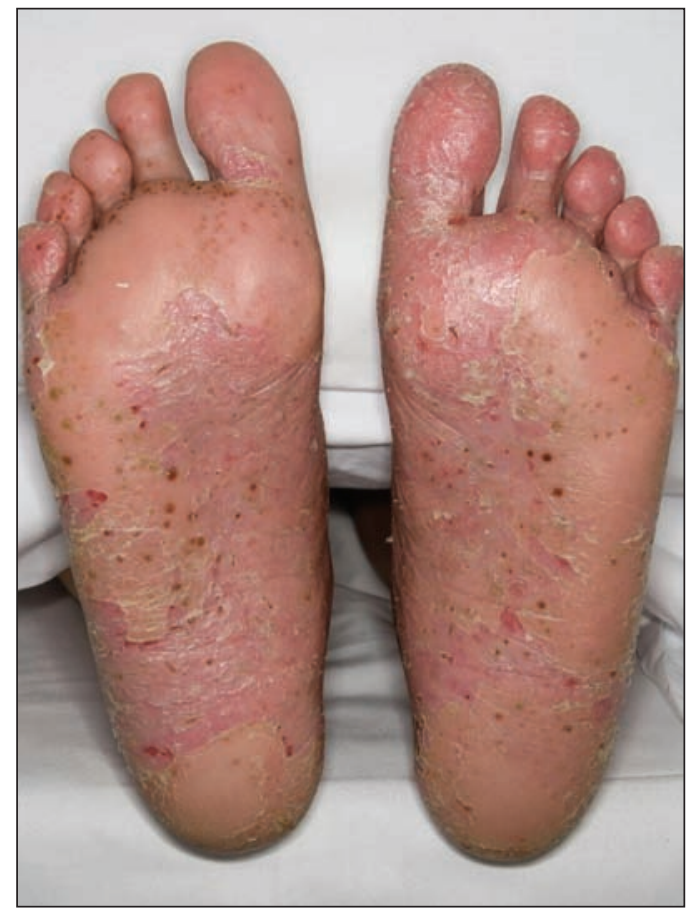

Figure 1: Soles of 46-year-old woman, showing thin erythematous plaques with desquamation, mixed with numerous brown macules and scattered pustules. with desquamation, mixed with numerous brown macules and scattered pustules, consistent with a diagnosis of palmoplantar pustulosis. Use of leflunomide, selected to treat her skin and joints, led to dramatic improvement of both, and her condition remained asymptomatic after 18 months of treatment.

Palmoplantar pustulosis is a chronic, relapsing, pustular eruption that is localized to the palms and soles. ${ }^{1}$ The cause is unknown, and it is unclear whether it is a distinct entity or a localized pustular variant of psoriasis. ${ }^{1}$ Palmoplantar pustulosis can be distinguished from dyshidrotic eczema by the presence of pustules (rather than vesicles), and from tinea by a negative finding on direct microscopic examination of potassium hydroxide-treated samples of scale. About $2 \%$ to $24 \%$ of patients with this condition have evidence of psoriasis elsewhere. ${ }^{2}$ Palmoplantar pustulosis is strongly associated with smoking, although smoking cessation may not decrease disease activity. ${ }^{1}$ The condition may also be associated with autoimmune thyroid disease, gluten sensitivity and SAPHO syndrome (consisting of synovitis, acne, pustulosis, hyperostosis and osteitis). ${ }^{1}$ Topical corticosteroids used under occlusion, psoralen plus ultraviolet A photochemotherapy, and acitretin have shown benefit in treating palmoplantar pustulosis. ${ }^{2}$ Although the clinical evidence is limited, there is some support for the use of tonsillectomy and for tumour necrosis factor$\alpha$ inhibitors in treating recalcitrant cases. ${ }^{1,3}$

\section{References}

1. Mrowietz U, van de Kerkhof PC. Management of palmoplantar pustulosis: Do we need to change? Br J Dermatol 2011;164: 942-6.

2. Chalmers RJ, Hollis S, Leonardi-Bee J, et al. Interventions for chronic palmoplantar pustulosis. Cochrane Database Syst Rev 2006;(1):CD001433.

3. Shmidt E, Wetter DA, Ferguson SB, et al. Psoriasis and palmoplantar pustulosis associated with tumor necrosis factor- $\alpha$ inhibitors: the Mayo Clinic experience, 1998 to 2010. J Am Acad Dermatol 2012;67:e179-85. 